\title{
Relation of Left Ventricular Diastolic Dysfunction to Serum Ferritin in Thalassemia Major
}

\author{
Aso Faeq Salih \\ Pediatric Department \\ College of Medicine \\ University of Sulaimani \\ Sulaimani, Iraq \\ aso.salih@univsul.edu.iq
}

\author{
Adnan M. Hamawandi \\ Pediatric Department \\ College of Medicine \\ University of Sulaimani \\ Sulaimani, Iraq \\ adnan.hasan@univsul.edu.iq
}

Volume 4 - Special Issue: 3rd International Conference on Health \& Medical Sciences: Insight into Advanced Medical Research (ICHMS 2019)

DOI:

10.24017/science.2019

.ICHMS.24

Received:

12 June 2019

Accepted:

6 July 2019

\section{Abstract}

A prospective study was conducted on 60 thalassemia major patients (33 males and 27 females) in whom the LV function and its parameters where assessed by echocardiography in relation to serum ferritin during the period from 2nd October 2007 to $2^{\text {nd }}$ February 2008 , in Sulaimani paediatric teaching hospital. Patient and method: The age ranges of patients were ranged between 3 - 18 years old. Diastolic function of $L V$ was assessed by (M-mode, D-mode and pulse dopplar study of mitral and pulmonary vein) done. Among 60 patients seen, $25 \%$ shows normal $\mathrm{LV}$ diastolic function, the rest are $13 \%$ relaxation dysfunction, $27 \%$ shows Psuedonormal diastolic dysfunction and 35\% shows restrictive pattern of $L V$ diastolic dysfunction. Mean serum ferritin in normal and abnormal diastolic $L V$ dysfunction was not so different. In addition nearly all $L V$ parameters as ( LVEDD, LVESD, LA diameter, aortic root diameter, IVC , $E, A, E / A$ ratio, A-E time, DT time, $S, D, R$ waves) where non significantly related to serum ferritin level, this means that $P$ value is less than 0.05 . This means that the level of serum ferritin has no relation with the above parameters in which $75 \%$ of those parameters were already abnormal in comparison to the age of the child. Another finding shows that $25 \%$ of normal diastolic function is seen in serum levels above $1500 \mathrm{ng} / \mathrm{l}$, in addition 50\% of diastolic dysfunction will associate serum ferritn of less than $500 \mathrm{ng} / \mathrm{l}$. P value is more than 0,05 this means that its non-significant. In conclusion there is a non-significant correlation between serum ferritin and $L V$ diastolic function, so serum ferritin is not dependant indicator for myocardial iron deposition.

Keywords: Ventricle, Thalassemia , Diastolic, Systolic, Sulaimani 


\section{INTRODUCTION}

Beta-Thalassemia major is an inherited hemoglobin disorder resulting in chronic hemolytic anemia An important complication of $\beta$-thalassemia major is iron deposition in the cardiac tissue resulting in cardiomyopathy and dysfunction[1].However, many studies reported that Bthalassemia major lead to LV systolic function, while few studies, with conflicting results, that alteration LV diastolic function happen in this disease [2, 3]. Many signs and symptoms of cardiac failure, previously attributed to impaired systolic performance, may be due to partly to altered diastolic properties of the ventricular chambers. Moreover, as many as $30-40 \%$ of all patients with typical symptoms of heart failure, have a normal systolic function [4]. However, in these patients, diastolic dysfunction is implicated as a major contributor. Transfusional iron may accumulate in liver and heart, causing damage to these organs. The resultant hemochromatosis prompts cardiac dysfunction, which remains the leading cause of death in $\beta$ thalassemia, despite advances in treatment [5]. The usefulness of echo-Doppler in thalassemia is based mainly in detecting established cardiac dysfunction [6]. For the evaluate iron condition the best parameter which is commonly used is serum Ferritin, as a positive correlation exists between serum ferritin concentration and iron stores [7]. This is reliable at low and normal levels, but loses accuracy as the iron load raises and the predictive value of serum ferritin on iron load may be poor [8]. In spite of these controversial data, cardiac disease remains the most frequent cause of death in thalassaemic patients, usually occurring in the third decade of life [9]. Echocardiography (Echo) is the examination of choice for routine heart evaluation. The simultaneous imaging of cardiac structure and function in real time helps in the acquisition of reliable diagnostic results. It is safe, economical, very easy to perform, and its use is widespread [6].The aim of the study is to confirm that is there is correlation of left ventricular diastolic function to serum ferritin in thalassemia major

\section{Patients and method}

This study was conducted during a period of 4 months started from 2 nd October 2007 to $2^{\text {nd }}$ February 2008, during which time 60 patients whom already diagnosed and registered as a case of thalassemia major in onco-haematological centre regardless they have cardiac problem or not taken and examined in paediatric cardiac unit in Slemani paediatric teaching hospital.

For each patient history and examination done, date of diagnosis, frequency of transfusion, date of splenectomy and type of splenectomy, chelating agent and its frequent using. As well as body weight and height and BSA (body surface area) calculated. Then each patient was sending to do serum Ferritin. An echocardiography done for each patient done by same operator and same machine (Cypress Siemens), with 2 available probes $3 \mathrm{MH}$ and $7 \mathrm{MH}$ frequency probes. For each patient study the following measures taken on $\mathrm{M}$ mode long axis parasternal view (LVEDD, LVESD, IVSs, IVSd, LAD, and AD) also by the same mode ejection fraction taken. (Fig.1). Statistical Analysis was done by the STAT version 12. TheChi-square was carried out to determine the relative importance of various variables. In some instances, ANOVA table test done to compare between mean variables. P-value less than 0.05 were considered statistically significant, and value of less than 0.01 was considered to be highly significant. 


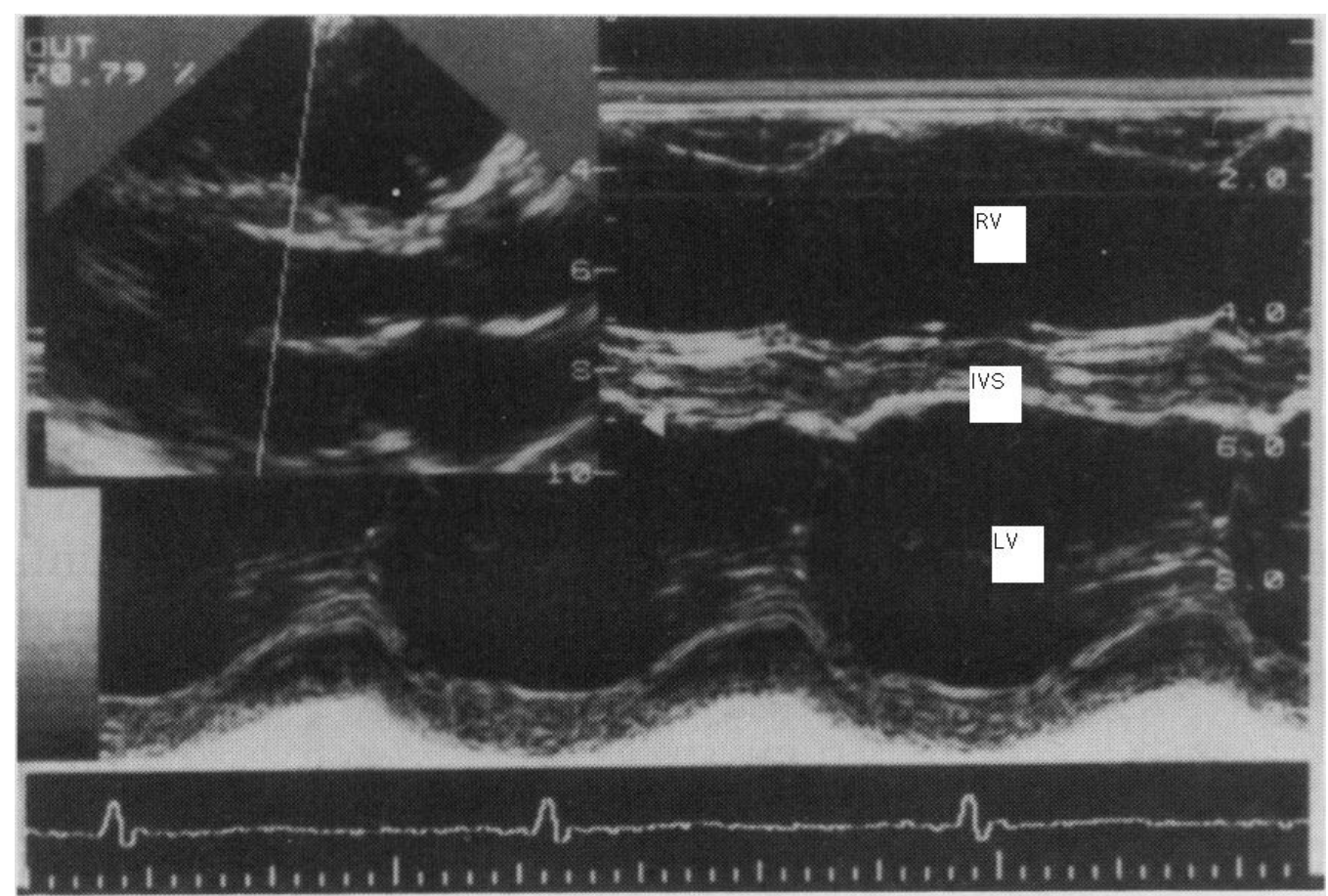

Figure 1: Shows $M$ mode parasternal view to obtain LV parameters and EF\% on apical view Pulse Doppler study done for mitral valve and measures taken on (E, A wave's peak velocity, aortic closure time and DT time).

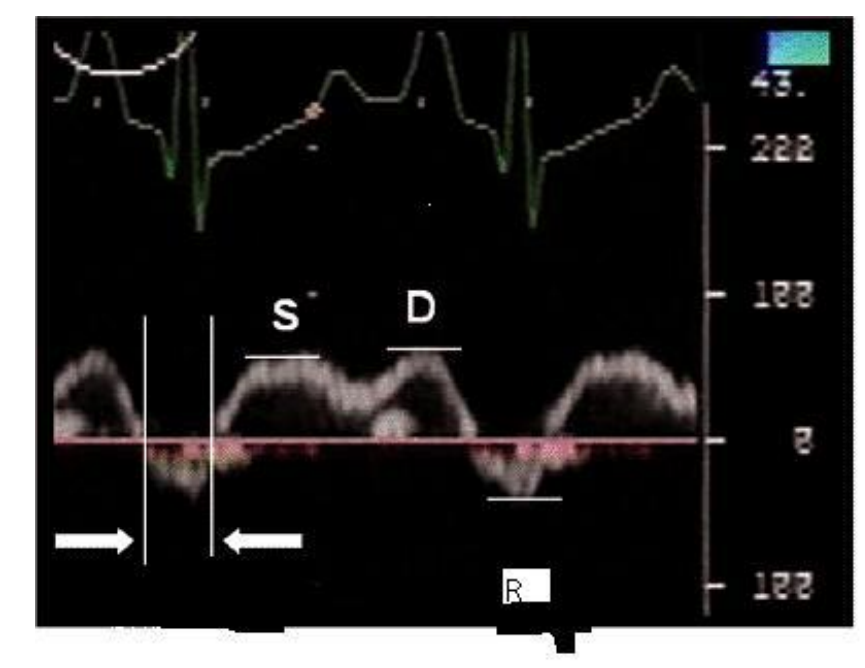

Figure 2: Shows pulse dopplar study of mitral valve flow pattern and its calculation. On same apical view Pulse Doppler study on right upper pulmonary vein and following measures taken as a peak velocity $(\mathrm{S}, \mathrm{D}$, and $\mathrm{R})$ waves. 


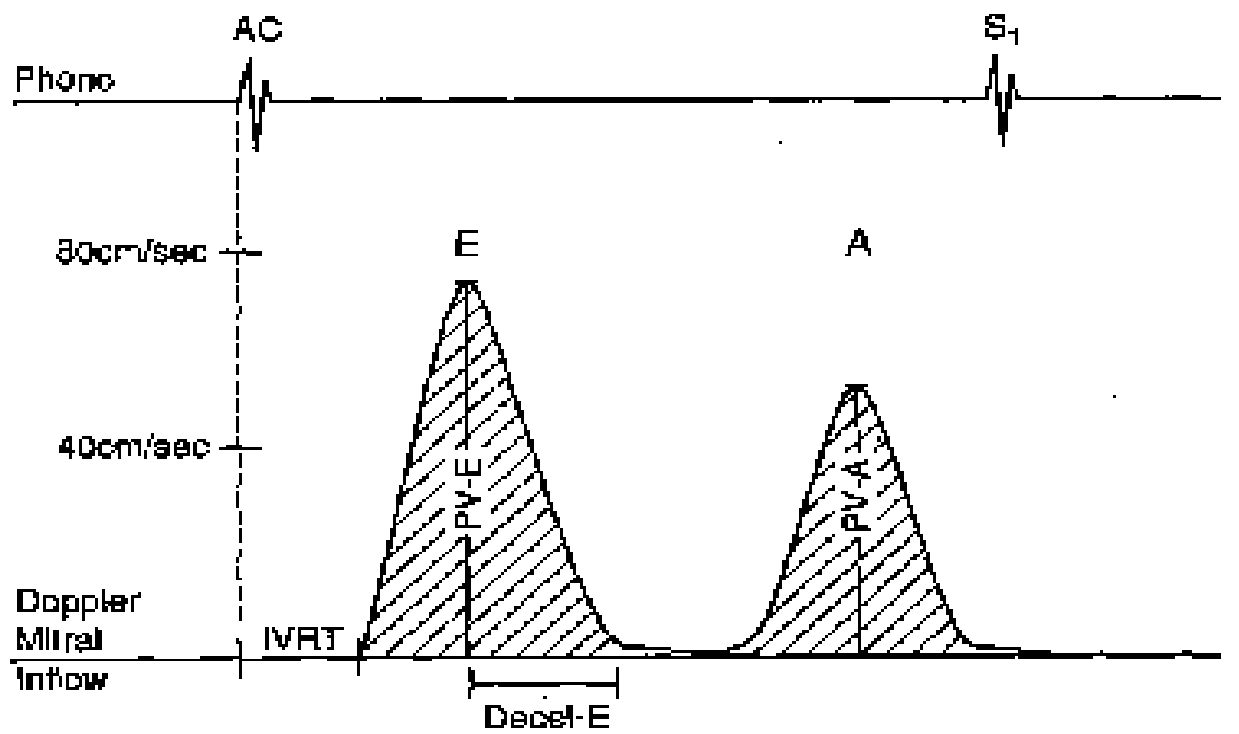

Figure 3: Shows pulse dopplar study of pulmonary vein flow and its calculation[10]

Then on basis of those measures the type of LV diastolic dysfunction decided as follows (Fig.4):

a. When DT time increased, A wave more prominent and D wave increased so it's called impaired relaxation.

b. When E normal and EA ratio also normal but $\mathrm{S}$ wave increased and there is $\mathrm{R}$ wave so it called Psuedonormal relaxation defect

c. When $\mathrm{E}$ wave peak and increased EA ratio, plus increase $\mathrm{D}$ wave and prominent $\mathrm{R}$ wave so it called restrictive diastolic dysfunction [11]. The values of each parameter corrected for age, weight and height.

\section{How to stage diastolic dysfunctions:}

Stage I diastolic dysfunction: impaired relaxation

In the earliest stages of diastolic dysfunction, the rate of ventricular relaxation is impaired. Delayed LV relaxation results in a slower decline in left ventricular pressure. This in turn results in a diminished gradient between the left atrium and left ventricle in early diastole, in turn resulting in a diminished mitral E-wave velocity. This also results in a lengthening of the isovolumic relaxation time and a lengthening of the E-wave deceleration time. As a result of these events in early diastole, there is a compensatory increase in late filling during atrial systole, producing an augmented mitral A wave. These changes occur in the setting where ventricular compliance and left atrial and left ventricular end-diastolic pressures are at near normal levels $[11,12]$.

In the pulmonary veins, delayed relaxation results in a decrement in flow during early diastole, resulting in an augmented systolic $S$ wave and a diminished $D$ wave. This results in an increased S-/D-wave velocity ratio. As atrial pressures are near normal at this stage of dysfunction, atrial systolic flow reversal remains absent or minimal.

Doppler tissue imaging of the lateral mitral annular velocities will demonstrate a decrease in the peak Ea velocity, corresponding to decrease in early diastolic ventricular relaxation. The $\mathrm{Ea} / \mathrm{Aa}$ velocity ratio will therefore be $<1$ in this setting $[2,13]$. 
Stage II: pseudonormal diastolic dysfunction

As diastolic dysfunction advances, ventricular compliance progressively diminishes along with continued abnormality in ventricular relaxation. This results in a compensatory increase in left atrial pressure. The increase in left atrial pressure has several effects: An increase in the left atrium to left ventricular pressure gradient in early diastole produces an increase in the mitral E-wave velocity and a shortening of the isovolumic relaxation time by producing early mitral valve opening. Progressive decreases in ventricular compliance result in shortening of the Ewave deceleration time[11].

The pulmonary venous flow profile features a decrement in the magnitude of the $S$ wave and an increase in the $\mathrm{D}$ wave, resulting in a diminished $\mathrm{S}$-/D-wave velocity ratio. The pulmonary venous A-wave velocity and duration will increase as ventricular compliance worsens. In adult studies, pulmonary venous A-wave velocities of $>35 \mathrm{~cm} / \mathrm{s}$ or pulmonary venous A-wave durations that exceed the mitral A-wave duration by at least $20 \mathrm{~ms}$ have been reported to distinguish normal mitral inflow profiles from pseudonormal mitral inflow profiles [13]. In the pediatric population, the difference between pulmonary venous A-wave duration and mitral Awave duration can identify children with elevated left ventricular filling pressures. However, these methods are adequately predictive only when the LV end-diastolic pressures are $>18 \mathrm{~mm}$ $\mathrm{Hg}$, which may be more applicable in the setting of restrictive physiology $[11,12,13,14]$.

The pattern of mitral annular velocities remains largely unchanged in the setting of pseudonormal dysfunction. Abnormal relaxation will again result in a diminished Ea velocity and an Ea/Aa velocity ratio of $<1$. Thus, Doppler tissue imaging is an important tool in distinguishing normal from pseudonormal mitral valve inflow profiles $[15,16]$. This is particularly true when obtaining technically adequate pulmonary venous A-wave profiles on transthoracic echocardiography proves difficult, or when pseudonormal dysfunction exists in the setting of modestly elevated left atrial pressure. An additional index of diastolic function that has been correlated to elevations in ventricular filling pressures is the ratio of transmitral $\mathrm{E}$ wave to lateral mitral annular velocity, or the $\mathrm{E} / \mathrm{Ea}$ ratio. This ratio has a close positive correlation with pulmonary capillary wedge pressures[14, 17].

Stage III diastolic dysfunction: restrictive physiology

As diastolic dysfunction worsens, a restrictive pattern emerges. Left atrial pressure and left ventricular stiffness are very high. The increase in left atrial pressure results in rapid inflow of blood into the left ventricular during early diastole, producing a large E wave. Low left ventricular compliance prohibits further filling in later diastole, resulting in a small A wave and further shortening of the E wave deceleration. Transmitral Doppler findings therefore feature an increased E-/A-wave ratio, with a mitral E-/A-wave velocity ratio typically $>2$, and further shortening of the E-wave deceleration time, which is typically less than the $150 \mathrm{~ms}$ in adult studies [13]. Of note, severe restrictive physiology results in a rapid rise in intraventricular pressures during diastolic filling, which will occasionally produce diastolic mitral regurgitation; these findings can be appreciated on color flow Doppler imaging [11, 18].

In the pulmonary veins, there is further worsening of the trend seen in pseudonormal dysfunction, with further decreases in the fraction of systolic pulmonary venous flow and further increases in the diastolic fraction, resulting in further decreases in the $\mathrm{S}$-/D-wave velocity ratio. The magnitude of the atrial systolic reversal frequently becomes quite pronounced. Doppler tissue imaging of the lateral mitral annulus in restrictive physiology will reveal a decrease in Ea velocities[11,19,16]. 


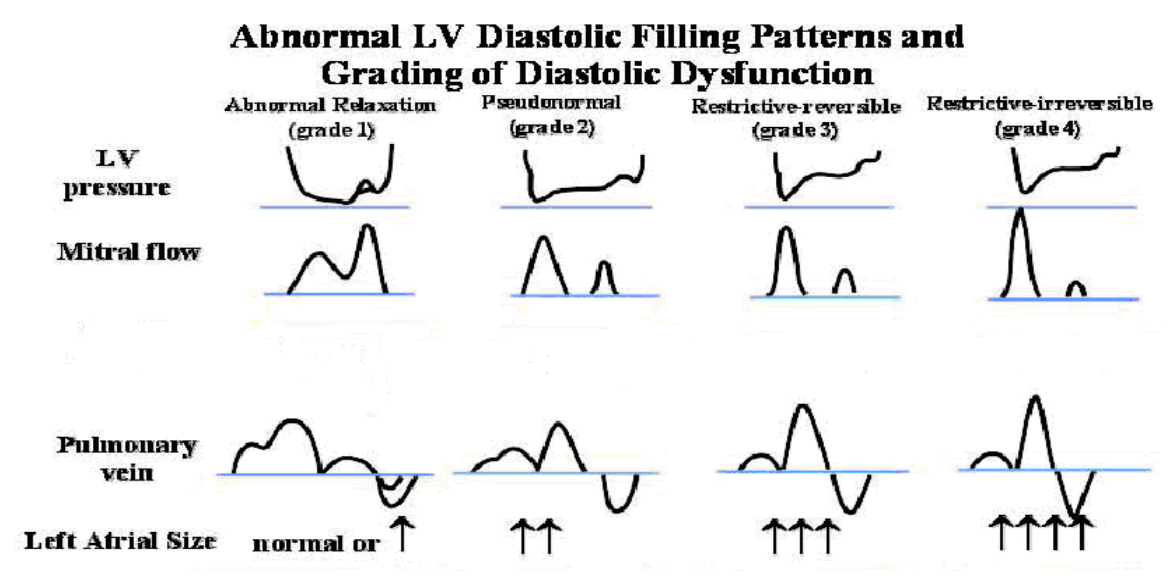

Figure 4: shows the different types of diastolic dysfunction of LV and characteristics of each dysfunction.

\section{RESULTS}

The study included 60 thalassemia major patients in whom 33 patient comprises $55 \%$ of total were male and 27 (45\%) of patients were female. Sex distribution according to different LV diastolic functions is shown in table 1

Table 1: Sex distribution in different kinds of diastolic function

\begin{tabular}{cccc}
\hline & \multicolumn{2}{c}{ Sex } & Total \\
\hline LV diastolic dysfunction & male & female & \\
\hline normal & 8 & 7 & 15 \\
\hline impaired relaxation & 6 & 2 & 8 \\
\hline pseudonormal & 5 & 11 & 16 \\
\hline restrictive & 14 & 7 & 21 \\
\hline & 33 & 27 & 60 \\
\hline
\end{tabular}

Non significant sex difference between groups of diastolic function $\mathrm{P}$ value is 0.1063

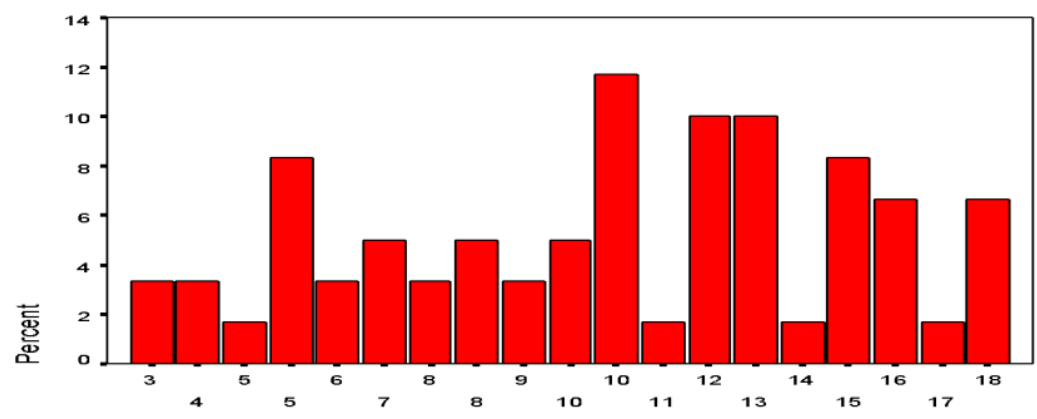

Age by years

Figure5: Age distributed by years

Table 2: Shows age distribution of study sample, there was statistically differences in the age with LV diastolic function which shows more in older age groups $(\mathrm{P}$ value $<0.05)$

Table 2: Chi-Square Tests of age with LV diastolic dysfunction

\begin{tabular}{cccc}
\hline & Value & df & Asymp. Sig. (2-sided) \\
\hline Pearson Chi-Square & 72,697 & 54 &, 046 \\
\hline
\end{tabular}


Table 3: Shows the mean serum ferritin of different kinds of left ventricular diastolic function in which it shows no obvious difference between mean serum ferritin value in normal and abnormal diastolic LV

\begin{tabular}{|c|c|c|c|c|c|}
\hline $\begin{array}{l}\text { LV diastolic } \\
\text { dysfunction }\end{array}$ & Mean & $\mathbf{N}$ & Percent & $\begin{array}{c}\text { Std. } \\
\text { Deviation }\end{array}$ & $\begin{array}{l}\text { LV diastolic } \\
\text { dysfunction }\end{array}$ \\
\hline Normal & 918,67 & 15 & 25,0 & 563,81 & Normal \\
\hline $\begin{array}{l}\text { impaired } \\
\text { relaxation }\end{array}$ & 955,25 & 8 & 13,3 & 482,15 & $\begin{array}{l}\text { impaired } \\
\text { relaxation }\end{array}$ \\
\hline Pseudonormal & 838,44 & 16 & 26,7 & 546,42 & Pseudonormal \\
\hline Restrictive & 1236,38 & 21 & 35,0 & 507,00 & Restrictive \\
\hline Total & 1013,35 & 60 & 100,0 & 542,95 & \\
\hline
\end{tabular}

Table 4: comparison of LV parameters in different ranges of serum ferritin and their each $\mathrm{P}$ value significance

\begin{tabular}{|c|c|c|c|c|}
\hline P value & more than 1500 & $500-1500$ & $1-500$ & ferritin range \\
\hline 0.354 & 9,42 & 11,05 & 11,27 & Age by years \\
\hline 0.645 & 42,642 & 44,230 & 44,938 & LVEDD \\
\hline 0.351 & 159,568 & 28,711 & 30,754 & LVESD \\
\hline 0.702 & 22,642 & 24,182 & 23,123 & LA dimension \\
\hline 0.292 & 14,116 & 14,218 & 15,877 & $\begin{array}{l}\text { Aortic } \\
\text { root dimension }\end{array}$ \\
\hline 0.792 & 9826 & 9832 & 9192 & IVC diameter \\
\hline 0.667 & 10,674 & 11,121 & 11,008 & E wave \\
\hline 0.806 & , 5579 & 6004 & ,5800 & A wave \\
\hline 0.454 & 22,126 & 20,739 & 19,523 & E/A ratio \\
\hline 0.064 & 863,684 & $1,093,214$ & 970,769 & A-E time \\
\hline 0.259 & $1,471,053$ & $1,661,786$ & $1,436,154$ & $\begin{array}{l}\text { E wave } \\
\text { deceleration } \\
\text { time }\end{array}$ \\
\hline 0.983 & 6184 & ,6246 & ,6138 & S wave \\
\hline 0.872 & ,6316 & ,6621 & 6685 & D wave \\
\hline 0.43 & , 4542 & ,5293 & ,5292 & $R$ wave \\
\hline 0.731 & 607,368 & 608,929 & 584,615 & EF at rest \\
\hline 0.053 & 366,263 & 475,000 & 398,462 & EF at excersize \\
\hline
\end{tabular}

Kurdistan Journal of Applied Research | 3rd International Conference on Health \& Medical Sciences: Insight into Advanced Medical Research (ICHMS 2019)| 230 
Table 5: Relation of serum ferritin levels to normal and three kind of diastolic dysfunction

\begin{tabular}{|c|c|c|c|c|c|}
\hline Serum Ferritin & Normal diastole & Impair relaxation & Pseudonormal & Restrictive & \\
\hline $\mathbf{0 - 5 0 0}$ & 6 & 1 & 4 & 2 & 13 \\
\hline 500-1500 & 4 & 6 & 10 & 8 & 28 \\
\hline More than 1500 & 5 & 2 & 2 & 10 & 19 \\
\hline Total & 15 & 9 & 16 & 20 & 60 \\
\hline P-value & & 0.1348 & 0.1207 & 0.1122 & \\
\hline
\end{tabular}

Chi square done including all the result is 0.746 , its non significant. Also done for each kind of diastolic dysfunction in relation to normal function of left ventricle and results as follow:

1. In impair relaxation diastolic dysfunction in relation to normal function $P$ value is 0.1348

2. In Psuedonormal diastolic dysfunction $P$ value is 0.1207

3. In restrictive diastolic dysfunction the $\mathrm{P}$ value is 0.1122

\section{DISCUSSION}

In 1960s, before the introduction of intensified transfusions and iron chelation therapy, poorly transfused patients with thalassemia major deceased most commonly in the second decade of life because of heart failure [20]. In 2000, in contrast, at least $50 \%$ of patients in a United Kingdom cohort were alive at $35 \mathrm{yr}$, while a $83 \%$ survival rate beyond $40 \mathrm{yr}$ was very recently reported [13]. Similarly, the incidence of heart failure in thalassemia major varies widely, following the highly variable age distribution and treatment in different cohorts. In 1964, a $63 \%$ incidence was observed at 16 yrs. of age $[20,21]$. Three decades later, in two different patient groups, congestive heart failure was observed in $33 \%$ and $37 \%$ of patients at a mean age of 20 and 23 yrs., respectively [22,23]. Diastolic dysfunction is a common condition in heart disease, contributing to the signs and symptoms of heart failure. Doppler echocardiography has been widely used for the non-invasive assessment of diastolic filling of the left ventricle [4]. Analysis of the mitral inflow pattern has provided useful information with respect to the level of filling pressure and the prognosis of selective group of patients. However, mitral flow dependence on several factors, such as age and loading conditions, limits its usefulness[24] . Data shows distribution of sex of cases that taken in which 55\% were male and $45 \%$ were male among 60 patients, a study done in University of Athens Medical School, "Laiko" Hospital, in Athens, in which it showed nearly the same percentage of LV dysfunction of both sexes [4]. There was no significant sex differences between different kinds of diastolic function were it mean that sex is not an affecting factor for LV diastolic dysfunction and also type of diastolic dysfunction, in which a study done in University of Athens Medical School, "Laiko" Hospital, in Athens, which shows there is no significant difference in heart affection between both sex in thalassemia [4].

Another study done in East Carolina university, Greenville, NC, USA, shows that there is non significant relationship between sex in normal and diastolic dysfunctional cases in thalassemia major [25]. Our results shows that with increasing age the LV diastolic dysfunction will increase and it's because of more frequent blood transfusion and iron deposition in the heart, and the relation between age and LV dysfunction is significant mean that age has significant influence on LV diastolic dysfunction. It's because that with progress aging the process of accumulation of iron within the myocardium become more exaggerated because of more frequent blood transfusion. In comparison to a study done in the Cardiology Departments of Athens General Hospital, Hippokration Hospital, University of Athens (Greece) Medical School, in which it shows the mean age that restrictive diastolic dysfunction (which is an last stage of diastolic 
dysfunction) occur after 10 years ages [26]. Among our patients $25 \%$ of patients shows echocardiographically normal LV function and $13 \%$ were shows isovolumetric relaxation defect, $27 \%$ shows psuedonormal diastolic dysfunction and $35 \%$ shows restrictive LV diastolic dysfunction. These results show that the restrictive pattern is more prevalent in iron overload cardiomyopathy, in a study done in Italy, shows that $50 \%$ of diastolic dysfunction cases are restrictive in nature [2]. It's because that restrictive diastolic dysfunction is the end result of the effect of iron deposition on myocardium. Our results did not show so much change in normal versus different kinds of LV diastolic dysfunction, in which a study done in Department of Internal Medicine, University of Athens Medical School, Laiko Hospital, Athens, in which it shows that there is no significant relationship between mean serum ferritin and both LV systolic and diastolic dysfunction[27]. It means that serum ferritin is not an indicator for cardiac affection, so we may have low serum ferritin with restrictive last stage LV diastolic dysfunction and vice versa. And this is explained that in low serum explain we may have high range of deposition of iron within myocardium and deteriorated LV diastolic function it may be due to previous high level of serum ferritin or most probably due to the fact that there may difference in myocardial uptake of iron from one person to another [27].

In other finding there was different echocardiography parameters related to LV dimension and function, in which the significance of each parameter in different kinds of LV diastolic function is calculated. In which it shows that all parameters taken on LV in relation to serum ferritin are statistically non significant, in which it mean that no parameters is dependants on serum ferritin as a screening value for the state of heart function and abnormalities, in which in comparison to another study done in the Cardiology Departments of Athens General Hospital, Hippokration Hospital, University of Athens, Greece, which shows in table 4 that that there are no relation between high or low level of serum ferritin level group in values of ( A,E waves E/A ratio, S,D, and also other parameters, which mean all results are non significant [27, 28]. Other results shows that there are statistically non significant relationships between serum ferritin values to different kinds of LV diastolic dysfunction. In which the iron deposited in the heart muscle has irrelevant relation to serum ferritin.

\section{CONCLUSION}

We conclude that sex is not affecting factor in dysfunctional LV diastole, but with advancing age LV diastolic dysfunction be more obvious. Serum ferritin is not a dependable parameter or test to evaluate deposited iron in the myocardium and Echocardiography will give us the real functional stat of the heart consequently it will reflect the iron deposit state of the myocardium. Deterioration of diastolic function of left ventricle will happen in staged manner in which it starts by impaired relaxation defect, then progress to pseudo-normal LV diastolic dysfunction and the to restrictive pattern of LV diastolic dysfunction. Most of LV diastolic dysfunction due to iron overload in thalassemia major is in form of restrictive pattern. Accordingly we recommend that thalassemia as a general and especially thalassemia major patients should be frequent monitoring by echocardiography .Serum ferritin is not an indicator of heart affection in thalassemias, so echocardiography by expert paediatric cardiologist is recommended and diastolic dysfunction should be evaluated More adavance work whiuld be done on tissue dopplar and cardiac MRI in future studies.

\section{REFERENCES}

[1] C. Chrysohoou, M. Greenberg, C. Pitsavos, D. B. Panagiotakos, V. Ladis, J. Barbetseas, et al., "Diastolic function in young patients with beta-thalassemia major: an echocardiographic study," Echocardiography, vol. 23, pp. 38-44, Jan 2006.

[2] P. Spirito, G. Lupi, C. Melevendi, and C. Vecchio, "Restrictive diastolic abnormalities identified by Doppler echocardiography in patients with thalassemia major," Circulation, vol. 82, pp. 88-94, 1990.

[3] D. Iarussi, G. Di Salvo, V. Pergola, P. Coppolino, M. A. Tedesco, G. Ratti, et al., "Pulsed Doppler tissue imaging and myocardial function in thalassemia major," Heart and vessels, vol. 18, pp. 1-6, 2003. 
[4] R. A. Nishimura and A. J. Tajik, "Evaluation of diastolic filling of left ventricle in health and disease: Doppler echocardiography is the clinician's Rosetta Stone," J Am Coll Cardiol, vol. 30, pp. 8-18, Jul 1997.

[5] G. Hahalis, D. Alexopoulos, D. T. Kremastinos, and N. C. Zoumbos, "Heart failure in beta-thalassemia syndromes: a decade of progress," Am J Med, vol. 118, pp. 957-67, Sep 2005.

[6] A. Aessopos, S. Deftereos, M. Tsironi, F. Karabatsos, J. Yousef, C. Fragodimitri, et al., "Predictive echoDoppler indices of left ventricular impairment in B-thalassemic patients," Ann Hematol, vol. 86, pp. 42934, Jun 2007.

[7] C. A. Finch, V. Bellotti, S. Stray, D. A. Lipschitz, J. D. Cook, M. J. Pippard, et al., "Plasma ferritin determination as a diagnostic tool," West J Med, vol. 145, pp. 657-63, Nov 1986.

[8] G. M. Brittenham, A. R. Cohen, C. E. McLaren, M. B. Martin, P. M. Griffith, A. W. Nienhuis, et al., "Hepatic iron stores and plasma ferritin concentration in patients with sickle cell anemia and thalassemia major," $A m$ J Hematol, vol. 42, pp. 81-5, Jan 1993.

[9] J. C. Wood, C. ENRIQUEZ, N. GHUGRE, M. OTTO-DUESSEL, M. AGUILAR, M. D. NELSON, et al., "Physiology and pathophysiology of iron cardiomyopathy in thalassemia," Annals of the New York Academy of Sciences, vol. 1054, p. 386, 2005.

[10] H. Yang, A. Woo, D. Monakier, M. Jamorski, K. Fedwick, E. D. Wigle, et al., "Enlarged left atrial volume in hypertrophic cardiomyopathy: a marker for disease severity," J Am Soc Echocardiogr, vol. 18, pp. 107482 , Oct 2005.

[11] H. D. Allen, D. J. Driscoll, R. E. Shaddy, and T. F. Feltes, Moss \& Adams' heart disease in infants, children, and adolescents: including the fetus and young adult: Lippincott Williams \& Wilkins, pp. 97-103,2008.

[12] M. Philip, H. Thomas; Assessment of diastolic function: what the general cardiologist needs to know; Heart , pp.681-695., 2005

[13]. H. Rakowski, et al. Canadian consensus recommendations for the measurement and reporting of diastolic dysfunction by echocardiography: From the Investigators of Consensus on Diastolic Dysfunction by Echocardiography. J Am Soc Echocardiogr ,pp.736-760,1996,

[14]. S.F. Nagueh, et al. Doppler estimation of left ventricular filling pressure in sinus tachycardia. A new application of tissue doppler imaging. Circulation .pp.1644-1650, 1998.

[15]. D.W. Sohn, et al. Assessment of mitral annulus velocity by Doppler tissue imaging in the evaluation of left ventricular diastolic function. J Am Coll Cardiol 1997; pp-474-480.

[16]. V. Rajagopalan, et al. Comparison of new Doppler echocardiographic methods to differentiate constrictive pericardial heart disease and restrictive cardiomyopathy. Am J Cardiol 2001;pp-86-94.

[17]. Sundereswaran L, et al. Estimation of left and right ventricular filling pressures after heart transplantation by tissue Doppler imaging. Am J Cardiol ,pp.352-357,1998.

[18]. Appleton CP, Hatle LK, Popp RL. Demonstration of restrictive ventricular physiology by Doppler echocardiography. J Am Coll Cardiol ,pp.757-768,1988.

[19]. M.J. Garcia, J.D. Thomas, A.L. Klein. New Doppler echocardiographic applications for the study of dias tolic function, J Am Coll Cardiol , pp.865-875,1998.

[20] M. A. ENGLE, M. Erlandson, and C. H. SMITH, "Late cardiac complications of chronic, severe, refractory anemia with hemochromatosis," Circulation, vol. 30, pp. 698-705, 1964.

[21] B. Modell, M. Khan, and M. Darlison, "Survival in beta-thalassaemia major in the UK: data from the UK Thalassaemia Register," Lancet, vol. 355, pp. 2051-2, Jun 102000.

[22] D. Grisaru, E. A. Rachmilewitz, M. Mosseri, M. Gotsman, J. S. Lafair, E. Okon, et al., "Cardiopulmonary assessment in beta-thalassemia major," Chest, vol. 98, pp. 1138-1142, 1990.

[23] N. F. Oliveri, D. G. Nathan, J. H. MacMillan, A. S. Wayne, P. P. Liu, A. McGee, et al., "Survival in medically treated patients with homozygous $\beta$-thalassemia," New England Journal of Medicine, vol. 331, pp. 574-578, 1994.

[24] C. Y. Choong, H. C. Herrmann, A. E. Weyman, and M. A. Fifer, "Preload dependence of Doppler-derived indexes of left ventricular diastolic function in humans," J Am Coll Cardiol, vol. 10, pp. 800-8, Oct 1987.

[25] B. Kircher, J. A. Abbott, S. Pau, R. G. Gould, R. B. Himelman, C. B. Higgins, et al., "Left atrial volume determination by biplane two-dimensional echocardiography: validation by cine computed tomography," Am Heart J, vol. 121, pp. 864-71, Mar 1991.

[26] D. T. Kremastinos, D. P. Tsiapras, G. A. Tsetsos, E. I. Rentoukas, H. P. Vretou, and P. K. Toutouzas, "Left ventricular diastolic Doppler characteristics in beta-thalassemia major," Circulation, vol. 88, pp. 1127-35, Sep 1993.

[27] A. Aessopos, D. Farmakis, A. Hatziliami, C. Fragodimitri, F. Karabatsos, J. Joussef, et al., "Cardiac status in well-treated patients with thalassemia major," European journal of haematology, vol. 73, pp. 359-366, 2004.

[28] D. T. Kremastinos, E. Rentoukas, S. Mavrogeni, Z. S. Kyriakides, C. Politis, and P. Toutouzas, "Left ventricular filling pattern in beta-thalassaemia major--a Doppler echocardiographic study," Eur Heart J, vol. 14, pp. 351-7, Mar 1993.

Kurdistan Journal of Applied Research | 3rd International Conference on Health \& Medical Sciences: Insight into Advanced Medical Research (ICHMS 2019)| 233 